\title{
Problematizations in Assisted Dying Discourse: Testing the "What's the Problem Represented to Be?"' (WPR) Method for Critical Health Communication Research
}

\author{
Wendy Pringle* \\ Art History and Communication Studies, McGill University, Montreal, QC, Canada
}

OPEN ACCESS

Edited by:

Heather Zoller,

University of Cincinnati, United States

Reviewed by:

Raihan Jamil,

Zayed University, United

Arab Emirates

John Lynch,

University of Cincinnati, United States

*Correspondence:

Wendy Pringle

wendy.pringle@mcgill.ca

Specialty section:

This article was submitted to Health Communication,

a section of the journal

Frontiers in Communication

Received: 30 April 2019 Accepted: 15 October 2019 Published: 13 November 2019

Citation: Pringle W (2019) Problematizations in Assisted Dying Discourse: Testing the "What's the Problem Represented to Be?" (WPR) Method for Critical Health

Communication Research.

Front. Commun. 4:58

doi: $10.3389 /$ fcomm.2019.00058
In this paper I test the methodological potential of a set of six questions, called the "What's the Problem Represented to be?," or WPR approach, borrowed from the field of discursive policy analysis (Bacchi, 2012a) for doing critical health communication (CHC) research. WPR is generative for critical health researchers because it shares the goal of challenging implicit and explicit causality and correlation within discourse. I apply these questions to examine the case of legalized medical assistance in dying (MAiD) in Canada, arguing that their simplicity and capaciousness facilitate critical responses to care disparities. This particular case is edifying for $\mathrm{CHC}$ researchers, because ideals of good living, "dignified" death, and the role of medicine are all crystallized within legal, media, and medical discourse on assisted dying. Debating what death can or should look like depends on a clearer understanding of how the logics of embodied difference (especially ability, race, and gender) are always already stacking the odds against equal political participation in, and access to health. The WPR approach flips the "proper objects" of health-centered critical research, beginning by scrutinizing proposed solutions in order to rethink the problems implicit therein. Asking such questions as "How has this representation of the "problem" come about?," "What effects are produced by this representation of the 'problem'?" and "How has it been (or could it be) questioned, disrupted and replaced?" productively situates the researcher between the discursive practices governing health and health care praxis itself. Ultimately, I argue that the WPR method encapsulates some of the best critical perspectives from the corpus of $\mathrm{CHC}$ research praxis, making it a helpful tool for advancing health communication research.

Keywords: policy, health, discourse, methodology, assisted dying, euthanasia, rhetorical analysis, research

\section{INTRODUCTION}

One key concern of critical health research is to intervene on questions of how bodies are governed by discourses of health and wellness. Attending to governmentality, however, encompasses a wide number of structural and agentic forces (Legg, 2005; Dean, 2006; Tierney, 2010), making concise interventions a challenge. Critical health communication $(\mathrm{CHC})$ research demonstrates a growing record of such work. In this paper, I argue that borrowing a research technique called the "What's the Problem Represented to be?," or the WPR method, from the field of critical policy studies has productive potential for $\mathrm{CHC}$ researchers. Specifically, WPR is a way to identify gaps, and "lay all 
the cards out on the table," so to speak, in the early, or conceptual stages of critical research design. The six-question method asks such questions as, "How has this representation of the "problem" come about?," "What effects are produced by this representation of the "problem"?" and "How has it been (or could it be) questioned, disrupted and replaced?" It is designed as a means of focusing on the diverse forces of governance, their historical genealogies, and social repercussions.

As the examples I discuss illustrate, the WPR method interrogates the subject positions that are made available through practices of representing the real. In this sense, the method is not a corrective to existing methodological strategies in $\mathrm{CHC}$ research, but an extension and crystallization of those $\mathrm{CHC}$ techniques that disrupt and intervene on how meanings and enactments of health construct and maintain inequality. I illustrate these points of connection, using examples from the work of Davis (2010), Berlant (2010), Keränen (2007) and Daley et al. (2017). Additionally, WPR's flexibility and simplicity holds pedagogical value, since pared-down adaptations of the six questions might be helpful for introducing students to the key impulses of $\mathrm{CHC}$ research practice in an accessible way. The six questions can be adapted or rearranged as needed to the context of the research. Finally, because the six questions may also be applied to the alternate proposals, the WPR method offers $\mathrm{CHC}$ research a template for refining techniques of resistance and translating critical research into strategies for political resistance, or recommendations for changes to policy and practice. Such an effort, argues Bacchi, "signals a commitment to include oneself and one's thinking as part of the "material" to be analyzed" (Bacchi, 2012a, p. 22). Because of this, WPR serves as a means of demarcating the critical vein of health communication research from the interpretive vein, by foregrounding relationships of power in the practice of research.

By engaging with the illustrative example of the legalization of medical assistance in dying (MAiD) in Canada, the stepby-step breakdown and analysis of the questions demonstrates how WPR gets to the crux of this complicated issue. I analyze how assisted dying was problematized differently by two key documents: the Supreme Court case that brought legal MAiD into effect, and the formal legislation that enacted the assisted dying policy. By attending to what is left unspoken in assisted dying discourse, the WPR approach zeros in on the ways that shared beliefs about disability say more about the anxieties of the able, than they reflect the realities of people with disabilities. The helpful chronology of the questions exposes how shifts in problematization (Bacchi, 2016), reshaped assisted dying discourse. While it initially focused on the right to self-determination in the final chapter of life, MAiD discourse refocused on vulnerability, a change which ultimately disempowered the ailing patients in question. In the following sections, I justify the link to critical policy studies, provide brief background on the case of legal assisted dying in Canada, and illustrate how it can be implemented to other objects of CHC research. Ultimately, I argue that the method's value for bolstering techniques in $\mathrm{CHC}$ research lies in its crystallization of the most incisive impulses of a critical approach into straightforward functional terms.

\section{Why Borrow Analytic Strategies From Critical Policy Studies?}

The critical sphere of policy scholarship considers "the ways in which "problems" are constituted elicit particular forms of subjectivity, influencing how we see ourselves and others" (Bacchi, 2012a, p. 22) putting it in good company with critical health communication approaches that treat "the types of knowledges that are developed and brought to bear upon health, illness, and medical care may be regarded as assemblages of beliefs that are created through human interaction and preexisting meanings" (Lupton, 2003b, p. 50; Zoller and Kline, 2008, p. 93). Within the field of critical health research, one of the key challenges that researchers are presented with is the breadth of institutional and structural forces shaping health discourse and practice. This is particularly true of key areas that have gained traction since the publication of Zoller and Kline's comprehensive review (Zoller and Kline, 2008), including the study of health policy as a critical communicative process and the development of context-sensitive models of health promotion, for which it is necessary to give in-depth attention to the diversity of structural and agentic forces at play. Furthermore, while there is a wealth of models for doing strictly interpretive work, as the editors of this research topic suggest, "doing" critical work, often deviates from interpretation. I argue that because of the applied nature of policy approaches, the strategies outlined here facilitates research with an eye to critical praxis, to intervening in the practices that reinforce health disparities.

Bacchi's approach to discourse analysis, which she terms a "policy-as-discourse" approach, scrutinizes presumed causality in the policy process. In other words, she calls on policy analysts to view policy not as producing a response to an objective problem, but rather, drawing on Goodwin (1996, p. 96), "as a discourse in which both problems and solutions are created" (Bacchi, 2000, p. 48). In this formulation, policy is treated not only as a tool of governance, but also as a social text providing fruitful grounds for interpretation. More specifically, she posits that policy analysis cannot set out to interpret or critique social problems of any kind, without first challenging how policy defines the problem itself to begin with. "Problems," explains Bacchi, "are "created" or "given shape" in the very policy proposals that are offered as "responses"” (Bacchi, 2000, p. 48). That is, policy (often erroneously) names and foregrounds the problems it proposes to solve. Disability policies, for example, frequently begin with the assumption that people with disabilities are the "problem" to be solved (Fulcher, 1989). Likewise, policies addressing the status of women in the workplace may fixate on lack of training as being the "“problem", responsible for "holding them back,"” when the problem is not women at all, but institutional gender bias (Bacchi, 2012a, p. 21). Bacchi's succinct reversal sets the researcher up to pose incisive questions and challenge presumed causalities at play in a wide range of social issues.

As I illustrate in the examples that follow, critical and interpretive policy analysis shares many of critical health communication's guiding affinities. More importantly, however, Bacchi's approach overlaps with critical scholarship that welcomes discord between conflicting accounts and views, 
encouraging researchers to keep open the "fertile tensions" between perspectives (Bacchi, 2000, p. 55). In this sense, the approach aligns with those critical communication scholars who welcome "dissensus," and are concerned "with the privileging of interests by particular constructions of reality" (Deetz, 2001, p. 15; Zoller and Kline, 2008, p. 93). Beyond the inclination toward challenging the central tenets of discursive texts, this vein of critical policy analysis is invested in interrogating the function of broader social processes at play in perpetuating the "problem" at stake. This, of course, is exactly what many critical health researchers embark on when they begin by rejecting the presumption that "health" is a stable category on which promotional campaigns, care practices and individual regimes of prevention are built. Health, as Metzl and Kirkland argue, is not a "a fixed entity that can be transported from one setting to another" (Metzl and Kirkland, 2010, p. 1) from the rich to the poor, for example. As CHC researchers know, policy and practice that assumes the stability of the problem itself misses the point. While this conviction is shared by critical policy studies and critical health communication, what does such analysis look like? Likewise, how should researchers go about zeroing in on an object for analysis that can yield impactful results?

\section{An Illustrative Case: The Legalization of Assisted Dying in Canada}

In the last twenty years, there has been an uptick in the number of jurisdictions debating the right to die worldwide. Belgium, Colombia, Luxembourg, the Netherlands, Switzerland, as well as six states in the United States (Oregon, California, Colorado, Montana, Vermont, and Washington) now all have some form of legal assisted dying protocol in place (Emanuel et al., 2016). Whether framed as assisted suicide, or medical assistance in dying, an increasing number of people at the end of life are making new demands of clinical care systems and the legal jurisdictions governing them. While the end of life is still broadly understood as a private affair, to be attended only by close family and health care workers, it is increasingly common for the dying to speak openly about their experiences (Van Brussel, 2014; West, 2018). Patients are no longer kept in the dark about a terminal prognosis, as was the norm in past decades, and are now encouraged to participate in the decisionmaking processes at the end of life (Walter, 1994). MAiD is an instructive case among these broader shifting end-of-life practices, because it provides an alternative option among the "increasingly flexible cultural scripts" (Timmermans, 2005, p. 993) in the final chapter of life. Despite this flexibility, as Keränen (2007) study of institutional discourse surrounding code status demonstrates, the unique challenges of end-of-life discussions are such that patients, families, and physicians and caregivers often feel that communication breaks down at the expense of patient experience. Given the high stakes associated with it, and the propensity for end-of-life discourse to create communication breakdown, MAiD is fertile ground for CHC analysis.

In 2016, Canada followed the US states and growing number of other countries worldwide that permit assisted dying. What makes the case of legalization in Canada such a compelling one is that in addition to reclassifying voluntary assisted dying from crime to care, the transition catalyzed frank and open discussions about the social function of medicine itself, and even more generally, what makes life liveable. Couched in these deliberations are deep concerns; actors in the debate have had to examine whether legalizing forms of suicide or euthanasia will reshape the fabric of social life altogether. Within the context of medical assistance in dying in Canada, the push toward a "permissive system" in which MAiD would be allowed in certain circumstances was understood as a way to limit suffering at the end of life. A key Supreme Court of Canada case, Carter v. Canada, which set the precedent for legal MAiD was centered around plaintiff Gloria Taylor, a woman diagnosed with amyotrophic lateral sclerosis (ALS) at age 61. This ruling focused on alleviating pain for those "who are suffering intolerably as a result of a grievous and irremediable medical condition" (Carter v. Canada (Attorney General), 2015, p. 6). The Carter v. Canada ruling found that the previous ban on assisting suicide actually deprived some people of life, since some may take their own lives prematurely for fear that they will be incapable of doing so when their suffering eventually becomes intolerable. This gesture reframed the right-to-die issue by positioning it as a violation of the guarantee of "the right to life, liberty and security of the person and the right not to be deprived thereof..." (Parliament of Canada, 1982) entrenched in the Constitution of Canada. At this stage in the policy process, the existing laws were identified as an obstruction to the guarantee of the right to a life without suffering. "End-of-life suffering," then, was considered the central problem at the heart of the issue.

Not unexpectedly, the proposed legalization of assisted dying set off contentions. Between 2012 and 2016, when proposed laws and a high-profile case in the Supreme Court were contemplating the decriminalization of assisting in the death of a terminally ill person, medical assistance in dying was bitterly debated in the Canadian media. Some of the most vocal opponents of MAiD argued that "social permission to die can evolve into social pressure to die" (Wente, 2015, para. 9). These fears fixed on the possibility that legalized MAiD might create a "slippery slope" whereby in addition to allowing terminally ill individuals to request $\mathrm{MAiD}$ in their final moments of life, the social climate might evolve into a point where the elderly could make such requests in order to avoid becoming a burden on their children. The figure of vulnerability loomed justifiably large over the controversy, particularly where the question of disability was present. Many wondered how any such laws could protect people with disabilities from abuse. Furthermore, some questioned how legalization of MAiD would address mental illnesses including Alzheimer's and depression, particularly where they might intersect with advanced old age or terminal illness (Chochinov et al., 2015).

During the deliberative processes, in addition to the moral debates about the permissibility of MAiD, the social function of medicine itself came into question. One group of doctors contended that no doctor who agreed to provide MAiD could at the same time "fulfill their role as protectors of the public and of life..." (Physicians Alliance Against Euthanasia n.d.), and that any procedure shortening life violated the Hippocratic 
Oath, and could therefore not constitute medicine at all. Van Brussel's analysis of news coverage of euthanasia in Belgium classed such arguments as "medical-rationalism," in which the strong belief in medical progress, and a focus on the technical dimension obscure the more existential and personal significance of death and dying (Seale, 1998, p. 77; Van Brussel, 2014, p. 17). Other care providers were more invested in revising the central tenets of medicine to accommodate an assisted dying protocol. Those who were willing to provide assisted dying contended that contemporary care practices should be revised to incorporate more flexible and patient-centered end-of-life options, including withdrawing lifesaving treatment, palliative sedation, and assisted dying procedures. Following this discourse, the role of doctors, drugs, and the "tangle of tubes" (Armstrong, 1987 , p. 565) that envelop the dying patient in the medical sphere take a backseat to the patient's own needs and wishes. The gulf between these disparate approaches were as wide as ever as the government was tasked with writing legislation that would comply with the Supreme Court's mandate that MAiD protocols could provide relief for people suffering intolerably from a "grievous and irremediable illness," (Carter v. Canada (Attorney General), 2015) while responding to concerns about abuses of the vulnerable. The breadth of arguments during this period illustrated how beliefs about the right to die and about what constitutes dignity in death were shifting.

In June 2016, legislation legalizing assisted dying passed in parliament and a set of restrictive eligibility criteria stipulated that the patient's death must be "reasonably foreseeable" to access MAiD (Nicol and Tiedemann, 2016). Many argued that this restriction unnecessarily excluded people who would suffer at length as a result (McLeod, 2016; CBC News, 2017). However, even many of those in favor of legal MAiD argued that there is no such thing as a "reasonably foreseeable" death. Furthermore, the restriction proved controversial within the context of disability. First, the matter was complicated by the difference in types of disability: those with lifelong conditions, and those who develop degenerative neuromuscular conditions later in life ${ }^{1}$. Secondly, advocacy groups and representative bodies were sharply split on the implications of access to MAiD for disabled people. Both sides argued that the other would foster exclusion and undermine equality for people with disabilities. For some, like bioethicist and disability rights activist Jennifer Johannesen, the reasonably foreseeable clause is considered a necessary safeguard to protect disabled people and those who suffer "from poverty, from disenfranchisement, from exclusion, from poor health care," and "poor palliative care" (Johannesen, 2016). The attorneys and plaintiffs in the Supreme Court case, spoke out against what they understood as a reversal of the precedent set by the case, arguing that denying MAiD to those without terminal illness or imminent death was "discriminatory" and "infantilizing" to disabled people (Lunn, 2016), would strip the autonomy granted to all Canadians by the Carter v. Canada Supreme Court ruling, and "trap people in their suffering" (McLeod, 2016). The "reasonably foreseeable" clause clearly emerged as the biggest point of contention at

${ }^{1}$ No one with a mental disability or illness is allowed access to MAiD under current laws. the center of the debate about the permissibility of assisted dying. This particular phrasing exposed deep anxieties about the temporal dimension of death and the role of medicine therein. Following Keränen's phrasing, it also holds the potential to "invite reflection about what life means to a patient, what death means, and what conditions are absolutely imperative and absolutely intolerable" (Keränen, 2007, p. 200).

Finally, in seeking to account for some of these concerns, the resulting amendment to the criminal code holds many clues about the "ideational logics" (Bacchi, 2012a, p. 21) shaping how Canadians understand dignity in death in the era of medicalization. The case is instructive for $\mathrm{CHC}$ researchers in that it served as a discursive forum for deliberating on shared Western ideals of medicine and autonomy. It presented, however, a complex set of conflicting beliefs and problems that proved challenging to parse. In the following section, I illustrate how the WPR method offers productive strategies for teasing out a critical analysis of this particular case, as well as theorize the potential of each WPR prompt to address concerns from other $\mathrm{CHC}$ research contexts.

\section{THE WPR METHOD}

On the surface, the six questions that constitute the WPR method might resemble a journalistic approach, one that considers "what, when, where, why, and how." However, despite their simplicity, the questions push the researcher to theorize across contemporary practices, and historical precursors-not always an easy or straightforward task. A critical approach can use WPR to consider how "particular problematizations favor certain solutions and preclude others" (Fairclough, 2013, p. 183; Bacchi, 2012 b) from the outset, and identify the next steps of the research design. In other words, WPR is a way to identify gaps, and "lay all the cards out on the table," so to speak, in the early stages of critical research. It is a way of homing in on opportunities for making critical in-roads. The questions are as follows:

1. What's the "problem" (for example, of "problem gamblers," "drug use/abuse," "gender inequality," "domestic violence," "global warming," "sexual harassment," etc.) represented to be in a specific policy or policy proposal?

2. What presuppositions or assumptions underpin this representation of the "problem"?

3. How has this representation of the "problem" come about?

4. What is left unproblematic in this problem representation? Where are the silences? Can the "problem" be thought about differently?

5. What effects are produced by this representation of the "problem"?

6. How/where has this representation of the "problem" been produced, disseminated and defended? How has it been (or could it be) questioned, disrupted and replaced? (2012, p. 22).

In identifying genealogical threads connecting problematizations to their radically contingent historical precursors, WPR facilitates imaging how social problems were once thought of otherwise and how they might be more 
progressively reimagined in the future. The WPR's reframing practice invigorates the possibilities for engaging a Foucauldian biopolitical perspective in $\mathrm{CHC}$ research strategies.

As the following examples from the case of MAiD illustrate, policy seeks to identify a singular problem in order to articulate a solution. Bacchi argues in reference to Australian health practices, this orientation is typical for policy, which is "conceived as a tool of governance to redress what needs fixing up in society" (WPR: What's the Problem Represented to Be?, 2014). Such an orientation is a reactive approach, because it is predicated on "fixed and identifiable societal problems" so as to name solutions in policy. For these reasons, argues Bacchi, we are governed through the problematizations themselves, rather than directly through policy, since it is in problematizing particular issues that policy makers enact their influence over society. By contrast, the six questions are strategically ordered so as to upset the naturalization of a social problem, thereby opening up room for critical intervention. In each of the following sections, I explore the goals of these questions in turn and test their capabilities for unpacking the trickiness of MAiD legislation in Canada. I also draw comparisons with existing approaches in the history of $\mathrm{CHC}$ research to illustrate how it meshes well with established strategies in critical health research.

\section{HOW DOES WPR TRANSLATE TO A CRITICAL HEALTH RESEARCH?}

\section{What's the Problem Represented to Be?}

The first question is intended to make visible the implicit problem representation within a specific policy. This, Bacchi explains, is the very crux of the method, since "what we propose to do about something reveals what we think needs to change and hence what we think is problematic" (WPR: What's the Problem Represented to Be?, 2014). Beginning with the WPR method's critical orientation, the first question sets the researcher up to move beyond face value assessments of social problems in order to unearth deeper ideational logics at play in the discourse at hand. By first naming the problems and their proposed solutions outright, $\mathrm{CHC}$ researchers can next examine deeper cultural contexts. The gesture seems simple, but it productively situates the researcher between the discursive practices governing health and health care praxis itself.

For example, Shapiro $(1981,2012)$ has drawn on this gesture of problematization to examine a case of health policy in Australia. Policy analysts on a government contract were tasked with addressing the high infant mortality rate among the aboriginal population. They had concluded that the disproportionate deaths were the result of the "seminomadic life of some of the aborigines" (Shapiro, 1981, p. 186). This explanatory politics, argues Shapiro, treats the assumption that indigenous people should adapt their mobility patterns to Western sedentary medicine as unproblematic. The fruitful reversal of problematization posits that the problem may in fact be with the Australian government's failure to adapt its delivery facilities to aboriginal migration (2012, p. 61). In producing a problematic aboriginal subject, the policy process of which Shapiro is critical presumes indigeneity to be always already engaged in "risky" behavior. By shifting problematization to the strategies of governance, the focus on a failure of maternal healthcare to adapt to migration opens up possibilities for critical examinations of the production of "governable subjects" (Mennicken and Miller, 2012) by the practices of governance themselves.

The central "problem," then, for pro-MAiD organizations such as Dying With Dignity Canada is prolonged end-oflife suffering. Sixteen months after the Supreme Court ruling, however, when the final piece of policy passed legal MAiD into effect, the problem was represented otherwise. The bill amending the criminal code used different language to represent the problem, shifting the focus of problematization. The "robust safeguards" (Wilson-Raybould, 2016, chap. 3) intended to protect some individuals from abuse took the form of an eligibility clause that focused on the temporal dimension of death. Specifically, it hinged on death's imminence as a precondition to accessing assisted dying. The MAiD legalization bill stipulates that assisted dying be provided for those with a "grievous and irremediable medical condition" which had to meet the criteria of their "natural death has become reasonably foreseeable" (Nicol and Tiedemann, 2016; Wilson-Raybould, 2016).

In short, as the legalization of MAiD passed from Supreme Court precedent to formal legislation, the language of the permissibility of the practice shifted from a focus on alleviating suffering, to expediating inevitable death. The new language was controversial, with many doctors decrying the "reasonably foreseeable" clause as meaningless from a clinical standpoint and therefore difficult to implement. This language of foreseeability is borrowed from civil and criminal law and relates to "risk, harm and the law of negligence" (Canadian Association of MAID Assessors and Providers, 2019, p. 3). As such, this language reflects the discursive nature of the legislation being an amendment to the criminal code, in contrast to something like health care policy. In its focus on culpability rather than care, the problem at the heart of MAiD is represented to be the potential abuse of vulnerability. The role of the state is therefore implied to be in the protection of the vulnerable. In the same gesture, the patients in question, those nearing death with some measure of "foreseeability" are cast as inherently vulnerable subjects. WPR's Question 1 helps to lay bare how a discourse of self-determination pivoted to one of vulnerability.

\section{What Presuppositions or Assumptions Underpin This Representation of the "Problem"?}

Bacchi's second question seeks to unearth the ideational logics informing a particular problematization. For those familiar with critical methodologies in health communication research, this question can serve as a gateway to a familiar set of concerns. That is, the question links specific problematizations to the conceptualizations of society that constitute them. Bacchi cites Foucault's Madness and Civilization as influential in her conception of WPR's second question (Foucault, 1965; WPR: What's the Problem Represented to Be?, 2014). Question 2 
encourages an approach similar to Foucault's in that it seeks cultural precursors to social phenomena, without relying on linear or causal historical argument. In focusing on discourse and social practices surrounding madness in history, Foucault was able to see how madness was thought about and how it came to be problematized, in this case for the first time. This focus on discourse and social practice offered a much clearer picture of madness than any other account from or about this era of history. Exposing the ideational logics, or "assemblages of beliefs" (Lupton, 2003b, p. 50) focuses the researcher on how interactions produce the kinds of body knowledges that shape the subject. In this sense, the method aims to articulate a certain measure of generalization beyond local concerns and interpretations. Like critical health research, in the WPR method "[p]articular persons and situations are artifacts used to understand the system of meanings through which particular persons and situations are composed and connected to the larger sociocultural context" (Deetz, 1992, p. 85; Zoller and Kline, 2008, p. 94). This means that the researcher can put cultural and ideological influence under the microscope, interrogating commonly accepted authoritative knowledges that determine what is "within the true" in our society (WPR: What's the Problem Represented to Be?, 2014).

As an example of how Question 2's approach is done well, consider Davis' study of obsessive-compulsive disorder (OCD) (2010). Like WPR's second step, Davis considers the styles of problematization that shape shared views. Davis contends that most studies of the disorder wrongly presume that OCD is a "universal and static" disease attributable to a particular pattern of neural physiology. Furthermore, explanations for a massive swell in the number of reported cases (from an estimated 0.005 to 0.5 percent of the general population in 1970 to one of the top four mental disorders in the world), Davis argues, tend to rely on the "it's always been around' myth" (Davis, 2010 , p. 124) the justification of which is unconvincing. In this instance, the DSM-V serves as the most commonly accepted, authoritative knowledge about OCD, but as Davis points out, the manual falls back to overly reductionist views, ignoring how "our definitions of mental health can be driven by complex biocultural factors" (Davis, 2010, p. 130). In attending to presuppositions and assumptions about the disorder, Davis illustrates how such an approach can expose where and how the medicalization of human behavior can shift perspectives.

Most critical approaches health communication share in the conviction that "our perceptions of reality are constituted as subjects attach meaning to phenomena and that these meanings arise through interactions" (Zoller and Kline, 2008, p. 93). Although myriad discursive forces shape the rights and rituals of health and wellness, $\mathrm{CHC}$ research need not account for all such influences. This second question of the WPR method is productively bounded. That is, the phrasing of the question encourages research design that zeroes in on select historical precursors, and the relationship they bear to contemporary phenomena. Cousins and Hussain (1984, p. 4) argue that "in accounts of governmentality, intelligibility not exhaustiveness is the key. What is sought is not an exhaustiveness of evidence but an intelligibility of problematizations..." (as cited in Osborne, 1997, p. 175). Anchoring the scope of inquiry to only those presuppositions which underpin this representation, advantageously fixates on one of the ways in which bodies are governed through discursive practice. WPR's Question 2 encourages a mode of interpretation that exposes what lies beneath surface-level assumptions about health and wellness. This question provides a fresh impetus to dig deeper into the origins and evolution of current iterations of the topic at hand.

In the case of MAiD in Canada, the problematization of vulnerability is underpinned by the view that we are (or should be) autonomous and invulnerable throughout life, that a good and healthy life is contingent on this invulnerability. The legislative framing fixated on a "reasonably foreseeable" death as a condition of its legal permissibility, a gesture which was intended to protect vulnerable individuals from having their lives cut short by accessing assisted dying.

By contrast, the global right-to-die effort pushing for the legalization of assisted dying worldwide, typically focused on patient experience, alleviating unnecessary suffering and giving individuals the right to self-determination in the final stage of life. Question 2 of WPR exposes the ways that a fixation on the vulnerability of potential MAiD patients inadvertently reifies the view that good healthy living necessarily excludes any kind of dependence or vulnerability.

\section{How Has This Representation of the "Problem" Come About?}

Following Foucault, the third question in the WPR method unpacks the genealogy of the implied problem. Within the context of critical policy analysis, this question serves to articulate the "players" involved in producing the policies themselves. Question 3 offers the opportunity for "consideration of the contingent practices and processes through which this understanding of the "problem" has emerged" (Bacchi, 2012a, p. 22). Analysts examining the origin of a problem representation might examine policy briefings to explore how the approach to the problem might have evolved or mutated over time. Question 3 is one strategy for avoiding the pitfalls of a presumed linearity that often befalls the problem definition and agenda setting stage of policy making (Barbehön et al., 2015). This critical orientation is intended to scrutinize the power relationships at play within policy networks. At this stage, a WPR approach considers which actors have shaped a given discourse or policy and how this has given shape to the coherence of a particular problematization.

Question 3 might best be explained with the example of abortion policy. While abortion was a common method of birth control for many years in nineteenth century Western nations, Britain's Offenses Against the Person Act of 1861 first proclaimed the illegality of the practice (Parliament: House of Commons, 1861; Sauer, 1978; Chamberlain, 2006). Therefore, 1861 serves as a point in time in which the problematization of abortion changed; at this moment abortion became a legal, criminal concern. Such a perspective casts knowledge as the product of a struggle. During this era, the emergence of modern medicine as a profession, the act was promoted by doctors who were eager to assert their authority over women's health. Bacchi argues that particular problematizations gain authority through struggle. The fact of the illegality of abortion was due in part to the struggle of the new profession of medicine against other unregistered practitioners (WPR: What's the Problem Represented to Be?, 
2014). This mode of thinking illustrates the radical contingency of knowledge on differential power relationships.

Attending to the underlying genealogical strata of problem representations offers emancipatory strategies for critical health researchers. In questioning "taken-for-granted assumptions" about who participates in political debates and policy processes, this aspect of the WPR method mimics the focus on agenda setting present in rhetorical analyses such as Perez and Dionisopoulos (1995) work on AIDS (Zoller, 2005), gendered analysis of the U.S. Department of Health and Human Service's Healthy People 2010 initiative, and Gillespie's (2001) analysis of asthmatic medicaid patients under managed care. Bacchi's third question aids in developing "a sharpened awareness of the forms of power involved in the shaping of problem representations" (Bacchi, 2012a, p. 23). In this sense, by calling the researcher to attend to knowledge-making practices, the WPR method holds potential for better understanding the communicative processes that inform the governance of health.

In Canadian assisted dying discourse, the focus on the "problem" of vulnerability came about in part as a result of its being conceptually linked to disability. The first federal rightto-die case was filed in 1993 by Sue Rodriguez, a woman with ALS who wanted access to medical assistance in dying (Rodriguez v. British Columbia (Attorney General), 1993). The following year, Robert Latimer, convicted of killing his severely disabled young daughter Tracy, lost his case subsequent appeals for "compassionate homicide," and served sixteen years in prison (CBC News, 2010). These instances were widely covered by the press and set a tone in the public imaginary in which the possibility of "allowable deaths" always carried the risk of endangering children like Tracy Latimer, or of devaluing the lives of people with disabilities. When plaintiffs in the Carter v. Canada Supreme Court ruling made arguments in favor of legalizing medically assisted death, their disabilities and disabling conditions were necessarily linked to these prior cases and their associations with vulnerability and the potential for abuse (Carter v. Canada (Attorney General), 2015). So, while the plaintiffs themselves understood MAiD to be a means of articulating their right to self-determination, many other groups including some disability rights groups and physician associations voiced concerns of abuse. Because of this, the ensuing legislation ushering in Canada's permissive system remained focused on the issue of vulnerability. The bill's preamble states: "Whereas it is important to affirm the inherent and equal value of every person's life and to avoid encouraging negative perceptions of the quality of life of persons who are elderly, ill or disabled; Whereas vulnerable persons must be protected from being induced, in moments of weakness, to end their lives" (Wilson-Raybould, 2016). This language positions disability as always vulnerable. That the following clause further links disability to weakness and vulnerability and suggests that people with disabilities are more susceptible to being persuaded to seek out MAiD by others. Since the previous two questions helped point out this shift in problematization, we might consider how this protectionist language is not inevitable, but rather the product of ableist paradigms of thought that seek to reinforce the invulnerability of able-bodied people.

\section{What Is Left Unproblematic in This Problem Representation?}

After tracing the discursive genealogy of problematization, the WPR method asks the researcher to consider what is left unspoken in the given discourse. This intervention is a way to arrive at the question: "Can the "problem" be thought about differently?" (Bacchi, 2012a, p. 22). Having contextualized and deconstructed what has been made central by a policy or discursive text, the fourth of Bacchi's six questions turns to what is left unspoken. Following this procedure encourages "careful scrutiny of possible gaps or limitations in this representation of the "problem," accompanied by inventive imagining of potential alternatives" (Bacchi, 2012a, p. 23). By asking what other interpretations there may be of the problem, Question 4 can be answered by taking a comparative approach, looking across time, or cross-culturally to see how issues have been problematized differently. Drawing on Foucault, Bacchi encourages the researcher to scrutinize and identify the "specific combination of practices and relations that give a problem a particular shape in a particular time and place" (WPR: What's the Problem Represented to Be?, 2014). Here Bacchi's approach shows its close affiliation with critical perspectives in communication, including those drawing on the cultural studies tradition that emphasize the "culturally situated nature of health communication interactions and processes" with reference to the structures of power that shape them (Zoller and Kline, 2008, p. 97; Dutta, 2008; Mokros and Deetz, 2013).

In attempting to resolve the matter the assisted dying in light of multiple competing public voices on the issue, the bill amending the criminal code was conceived as a means of "permitting access to medical assistance in dying for competent adults whose deaths are reasonably foreseeable," while striking a balance with the "autonomy of persons who seek medical assistance in dying, on one hand, and the interests of vulnerable persons in need of protection and those of society, on the other" (Wilson-Raybould, 2016). Autonomy, here, is understood as a set of rights, universal to all those patient/citizens subject to care under Canada's universal health care system. Furthermore, it has been informed by the legacy of abortion rights which established a notion of personal autonomy that encompassed "control over one's bodily integrity free from state interference" (Rodriguez v. British Columbia (Attorney General), 1993; R. v. Morgentaler, 1993; Carter v. Canada (Attorney General), 2015). These linkages to abortion rights seem to gesture to MAiD's liberatory power, by granting dying patients greater selfdetermination at the end of life. Left unspoken however, is that the power to determine the reasonable foreseeability of death is still granted to physicians. Although intended as a safeguard, in leaving the responsibility for the decision to permit MAiD with the medical establishment, the law reifies its status as ultimate authority. Challenging the ultimate authority of medicine over the final moments of life had been one of the primary goals of the right-to-die movement that fostered political momentum for MAiD legislation. Linking vulnerability to disability as the policy does, exposes how as disability scholars such as GarlandThompson have noted, disability is constructed as a "repository" for social anxieties about "vulnerability, control and identity" 
(1997, p. 173). In this sense, the legislation which is intended as a protectionary measure against abuses of vulnerable people, also works unintentionally to perpetuate the notion that people with disabilities are necessarily vulnerable, and by extension, that able-bodied people are invulnerable, or at least unlikely to be vulnerable in the same ways.

Like other established critical and interpretive techniques in health communication, this question asks the researcher to consider how the construction of problem and solutions may be "deflecting attention from other (marginalized) interests" (Zoller and Kline, 2008, p. 102). Lauren Berlant's study of obesity discourse might be understood as taking the same methodological orientation to health as does WPR's fourth question (Berlant, 2010). What's missed in all the efforts to condition people to make better choices about their health by eating well and exercising, she argues, is that racialized poverty and exploitative capitalist work culture shape day-to-day health practices more than does any kind of will power or autonomy. Such an approach lay bare the fiction of neoliberal invulnerable self (West, 2018), whose autonomy and self-determination are expected to make or break the push for achieving or maintaining healthiness. As Berlant's study illustrates, health-centered critical research is attuned to challenging the problematization of certain health practices. Question 4 carries the imperative to revisit the political nature of health discourse. Attending to the silences in a particular mode of problematization refocuses attention on how and why some subjects are problematized while others are not.

\section{What Effects Are Produced by This Representation of the "Problem"?}

Question 5 of the WPR method addresses representation, meaning, and effect. In adapting this question to the context $\mathrm{CHC}$ research, it is evident that it can be used to examine how a particular health discourse, practice or process may contribute to health and care disparities. This question is intended to stimulate "considered assessment of how identified problem representations limit what can be talked about as relevant, shape people's understandings of themselves and the issues, and impact materially on people's lives" (Bacchi, 2012a, p. 22). Such an approach is key to critical research's insistence on considering the material and lived effects that discourse, policy or governance may have on the subjects in question. It positions the researcher to think holistically about who stands to risk the most when communicative health practices are enacted in society, whether at the level of local communities, or global populations.

Representing vulnerability as the central problem at the heart of MAiD legislation has the effect of reproducing a version of healthy liberal subjectivity that is autonomous and invulnerable. As Bacchi suggests, such an analysis is not conceived as a cause and effect relationship, but rather examines how we are governed through problematizations, a process which has the potential to constitute us as governable subjects. While it is of course critical that people be protected from ending their lives prematurely, the legislation itself has been denounced for excluding access to many of the individuals that MAiD was understood to be assisting, including, some have argued, the original plaintiff on the Supreme Court Case, who lobbied for the legalization of MAiD in the first place (McLeod, 2016). Immediately following the passage of the Criminal Code Amendment (Bill C-14), a young woman with spinal stenosis named Julia Lamb filed a court challenge to the bill on the basis that it discriminated against people with disabilities. In a sense, the bill and its restrictions might be understood as protecting ableist conceptions of good living, where life is worth living up until it isn't, where bodies are healthy and able until disability creeps in and a medical authority predicts that death is reasonably foreseeable. Herein lies the value of Bacchi's fifth question. It scrutinizes how political and discursive formations can construct limits imposed on what can be thought and said (WPR: What's the Problem Represented to Be?, 2014), and, particularly in the case of assisted dying discourse, calls attention to the impact such practices can have on conceptions of life and death (Dean, 2006).

Critical health communication researchers and other scholars attending to medicine from a critical-social perspective frequently attend to the material consequences that social systems of power may have on peoples' lives, whether as a result of inequities produced by gender, class, race, or other differences (Waitzkin, 1991; Briggs, 2002; Lupton, 2003a; Murphy, 2012). Having pushed the researcher to articulate the underlying premises of a problem's representation, examine its emergence in practice and process, and scrutinize the gaps in its logics, the fifth question in the WPR method's procedure pushes the researcher to move toward the political implication of discursive formations. Pairing this consideration with the earlier steps in WPR analysis encourages an outlook that leaves the complex plurality of health care discourse intact. To borrow from Zoller and Kline's commentary on the work of Nadesan (2013), the question invites a research practice that will "address relationships among materiality/biology, culture, and identity, without reifying these complex concepts" (Zoller and Kline, 2008, p. 106). Finally, Question 5 primes the researcher to next consider how such a problematization circulates in popular discourse.

\section{How/Where Has This Representation of the "Problem" Been Produced, Disseminated, and Defended?}

Having called on the researcher to lay the groundwork necessary for critical intervention, the sixth question turns toward dissemination and resistance. The sixth question asks: How/where has this representation of the "problem" been produced, disseminated and defended? How has it been (or could it be) questioned, disrupted and replaced? (Bacchi, 2012a, p. 22). This question, the final of the six, allows the researcher to consider "actors" such the media as co-constitutors of problem representation. It is "explicitly concerned with resistance" and how "challenges to pervasive problem representations take place (WPR: What's the Problem Represented to Be?, 2014). This question works in tandem with Question 3 in order to imagine alternatives and to "destabilize taken-for-granted truths" (WPR: What's the Problem Represented to Be?, 2014). With particular relevance to analyses that focus on media messages, 
the approach is not concerned with intentional or strategic framing, or misleading shaping of messages, but rather about the subject positions that are made available through practices of representing the real. Bacchi is adamant that the Foucauldian origins of the WPR method do not preclude resistance, but rather encourage it. Citing the importance of the medical definition of homosexuality to the gay movement, Foucault argues that although discourses of medicalization may consist in forces of oppression, they can often also precipitate means of resistance as well (Foucault, 1998, p. 168). Although the standing medical definition of homosexuality was oppressive, it served as a point of departure for resistant political intervention. A parallel contemporary example lies in trans politics of resistance. While the DSM IV (the Diagnostic Statistics Manuals for "Mental Misorders") pathologized trans bodies through the language of deviance (Bevensee, 2014, p. 100), its inclusion in medical manuals can help trans people access gender confirming surgeries through their insurance coverage (Corneil et al., 2010), and thereby carries the potential for such resistance to normalizing regimes of oppression. The sixth question's critical focus on the role of representation attunes the WPR method to honing alternative political strategies, illustrating its usefulness to advancing critical methods.

While more conventional health communication approaches have offered valuable research on health campaigns and behavior, many such studies could benefit from the holism of WPR. For example, research scrutinizing the rollout of at vaccine awareness campaigns and subsequent public response might seem to be examining how the problem of immunization has been, as the question prompts, "produced, disseminated and defended," but may not intervene at the root of the problem. One such example is Briones et al.'s (2012) study of vaccine coverage on YouTube, which traces positive and negative beliefs about the HPV vaccine. Conversely, if such a study were to begin from the perspective of problematization, as the WPR method encourages, studying HPV discourse would engage social and historical precursors to vaccine hesitancy. This is how the six questions work well together. Beginning from problematization (WPR Question 1) and attending to inherent presuppositions or assumptions (WPR Question 2), the research could engage dimensions like the "feminization of HPV" (Daley et al., 2017, p. 141), a virus which in reality is carried by people of any gender. Such an approach could then link the gendered nature of HPV vaccine discourse to concerns about the gendered nature of medicalization, or to the presupposition of risk with regard to female sexuality. This critical foundation, rooted in history and culture, engenders scholarly interventions with more progressive momentum. It gestures to the ways that health discourses can shape identity and reinforce normative understandings of illness.

$\mathrm{CHC}$ research is often invested in examining how beliefs about health, wellness, and medicine are produced and recirculated in diffuse discursive arenas including media and public debate. The sixth WPR question is the most closely akin to established techniques of interpretive and critical health communication research, which typically attends to the ways that "media representations produce and reproduce social knowledge" (Zoller and Kline, 2008, p. 101; Seale, 2003; Zoller and Dutta, 2009;
Reitmanova et al., 2015). The value that Bacchi's particular phrasing offers for $\mathrm{CHC}$ researchers is in its function of linking the oppressive power of normative medicalization to its inherent potential for resistance.

With regard to the example of assisted dying discourse in Canada, the representation of vulnerable disability as the problem central to the issue of medical assistance in dying exposes how limited understanding of disability unproductively universalizes the disabled body. Social fears about vulnerability, that are due in large part to a culture of health that overvalues total autonomy and independence (Mitchell and Snyder, 1997; Ho, 2008; Kafer, 2013), where health is often understood as a matter of rigor or willpower (Lupton, 1995). This hegemonic conception of the body might be understood as causally linked to the ways that, as Harvey suggests, under neoliberal capital we define sickness as the inability to work (Harvey, 2000). The individualist view is in part an ideological by-product of a culture of health based on privatized care and a politics of deservingness that links good health care to hard work and full-time employment. Not only do people with disabilities face social barriers to living as they choose (Tremain, 2005; Schweik, 2009; Saxton, 2013; Zola, 2017), but by offloading social fears about vulnerability onto disability, medicalized assisted dying also ultimately further limits options for people living with disabilities as well.

\section{CONCLUSION}

Testing each of the six WPR questions for their relevance to doing health communication research reveals many productive overlaps with some critical approaches in the field. Furthermore, the consecutive breakdown of each critical consideration pushes the researcher to cast a broad net over the social, economic, and cultural forces at play in shaping discourses of health. Bacchi's research directly articulates how the method engages the critical interventions of Foucault and for better understanding how answers to each of the six questions are interconnected. It is particularly well-suited to disentangling complex problems-like the case of legalized MAiD_since it provides a roadmap for navigating the essential meaning-making practices at the heart of health care decision-making and of debates about living (or dying) well.

The WPR method of analysis breaks some of the most useful strategies for interrogating health discourse into a manageable step-by-step procedure. It asks the researcher to scrutinize the framing of problems and solutions, digging deeper into a key set of influences. It calls attention to deeper ideological forces that shape taken-for-granted assumptions about health. It gestures to the individuals, institutions and other powers involved in perpetuating such problems. It refocuses attention to marginalized people (as illustrated in disability views on MAiD) and perspectives (as in the cases of British abortion law). Attention to such views are generative for rethinking health discourse and governance, since they may be used to leverage for more equitable conditions. It demands for an intervention that acknowledges the effects of discourse on the lived material 
realities of the people affected. Finally, the WPR method pairs negative/oppressive practices of representation to their inherent potential for resistance and political intervention. This productive pairing is conducive to moving beyond interpretation and toward, for example, articulating resistance, or proposing alternatives to the status quo.

Bacchi's focus on problematization helps expose how through its fixation on culpability, MAiD policy inadvertently foregrounds vulnerability over autonomy, further limiting an already fraught patient and caregiver dynamic. I have explored how this is linked to an individualist notion of health; a concept well established by $\mathrm{CHC}$ research in other stages of life. The method unearths some of the historic and culturally specific aspects of Canada, including how fears of abuse have precipitated such beliefs. By attending to what is left unspoken in the discourse, the WPR approach zeros in on the ways that shared beliefs about disability say more about the anxieties of the able, than they reflect the realities of people with disabilities, or others at the end of life. With the call to explore the material and lived effects of representation, the method points out how despite being conceived as promoting autonomy, the law in question upholds ableist conceptions of good living. Finally, helping to link the discourse of vulnerability to a culture of health that overvalues total autonomy and independence, the WPR method helps to situate the problem at hand within broader debates in

\section{REFERENCES}

Armstrong, D. (1987). Silence and truth in death and dying. Soc. Sci. Med. 24, 651-657. doi: 10.1016/0277-9536(87)90308-X

Bacchi, C. (2000). Policy as discourse: what does it mean? Where does it get us? Disc. Abingdon 21, 45-57. doi: 10.1080/01596300050005493

Bacchi, C. (2012a). "Introducing the 'What's the Problem Represented to be?' approach," in Engaging With Carol Bacchi: Strategic Interventions and Exchanges, eds A. Bletsas and C. Beasley (Adelaide, SA: University of Adelaide Press), 21-24.

Bacchi, C. (2012b). Why study problematizations? Making politics visible. Open J. Polit. Sci. 2, 1-8. doi: 10.4236/ojps.2012.21001

Bacchi, C. (2016). Problematizations in health policy: questioning how "Problems" are constituted in policies. SAGE Open 6:2158244016653986. doi: $10.1177 / 2158244016653986$

Barbehön, M., Münch, S., and Lamping, W. (2015). "Problem definition and agenda-setting in critical perspective," in Handbook of Critical Policy Studies, eds F. Fischer, D. Torgerson, A. Durnová, and M. Orsini. Available online at: http://ebookcentral.proquest.com/lib/mcgill/detail.action?docID=4501526 (accessed: February 22, 2019).

Berlant, L. (2010). "Risky bigness: on obesity, eating, and the ambiguity of "Health."' in Against Health: How Health Became the New Morality, eds J. M. Metzl and A. Kirkland (New York: NYU Press), 26-39.

Bevensee, E. (2014). Transwomen, the prison-industrial complex, and human rights: neoliberalism and trans-resistance. Soc. Without Borders 9, 96-110.

Briggs, L. (2002). Reproducing Empire: Race, Sex, Science, and U.S. Imperialism in Puerto Rico. Retrieved from: http://hdl.handle.net/2027/heb.04341 (accessed August 02, 2018).

Briones, R., Nan, X., Madden, K., and Waks, L. (2012). When vaccines go viral: an analysis of HPV vaccine coverage on YouTube. Health Commun. 27, 478-485. doi: 10.1080/10410236.2011.610258

Canadian Association of MAID Assessors and Providers (2019). The Clinical Interpretation of "Reasonably Foreseeable." Victoria, BC: Canadian Association of MAID Assessors and Providers, 11.

Carter v. Canada (Attorney General). (2015). 1 SCR 331. the field and points to possibilities for critical resistance, and progressive policy revisions.

\section{DATA AVAILABILITY STATEMENT}

The raw data supporting the conclusions of this manuscript will be made available by the authors, without undue reservation, to any qualified researcher.

\section{AUTHOR CONTRIBUTIONS}

The author confirms being the sole contributor of this work and has approved it for publication.

\section{ACKNOWLEDGMENTS}

Many thanks to Amanda Coles and the participants of the November 2018 WPR Policy Analysis Workshop held at Centre de recherche interuniversitaire sur la mondialisation et le travail at l'Université de Montréal, as well as my insightful graduate and undergraduate students in the Winter 2019 Critical/Interpretive Policy Studies seminar in the Department of Art History and Communication at McGill University for the conversations generative for this study.

CBC News (2010, December 6). “Compassionate homicide': The law and Robert Latimer|CBC News. CBC. Retrieved from: https://www.cbc.ca/news/canada/ compassionate-homicide-the-law-and-robert-latimer-1.972561

CBC News (2017, May 23). B.C. Woman Joins Fight to Overturn Rightto-Die Limitations. Retrieved from: https:/www.cbc.ca/news/canada/britishcolumbia/robyn-moro-bccla- 1.4127446 (accessed July 4, 2018).

Chamberlain, G. (2006). British maternal mortality in the 19th and early 20th centuries. J. R. Soc. Med. 99, 559-563. doi: 10.1177/014107680609901113

Chochinov, H. M., Frazee, C., and Pelletier, B. (2015). Consultations on PhysicianAssisted Dying-Summary of Results and Key Findings. Retrieved from: http:// www.justice.gc.ca/eng/rp-pr/other-autre/pad-amm/index.html (accessed January 03, 2017).

Corneil, T. A., Eisfeld, J. H., and Botzer, M. (2010). Proposed changes to diagnoses related to gender identity in the DSM: a world professional association for transgender health consensus paper regarding the potential impact on access to health care for transgender persons. Int. J. Transgend. 12, 107-114. doi: 10.1080/15532739.2010.509205

Cousins, M., and Hussain, A. (1984). Michel Foucault. London: Macmillan Publishers Limited. doi: 10.1007/978-1-349-17561-1

Daley, E. M., Vamos, C. A., Thompson, E. L., Zimet, G. D., Rosberger, Z., Merrell, L., et al. (2017). The feminization of HPV: how science, politics, economics and gender norms shaped U.S. HPV vaccine implementation. Papillomavirus Res. 3, 142-148. doi: 10.1016/j.pvr.2017.04.004

Davis, L. J. (2010). “Obsession: against mental health," in eds J. M. Metzl and A. Kirkland, Against Health: How Health Became the New Morality (New York: NYU Press), 121-132.

Dean, M. (2006). "Governmentality and powers of life and death," in Analysing Social Policy: A Governmental Approach, eds G. Marston and C. McDonald (Cheltenham: Edward Elgar Publishing), 19-35.

Deetz, S. (1992). Democracy in an Age of Corporate Colonization: Developments in Communication and the Politics of Everyday Life. Albany, NY: SUNY Press.

Deetz, S. A. (2001). "Conceptual foundations," in The New Handbook of Organizational Communication: Advances in Theory, Research, and Methods, eds F. M. Jablin and L. Putnam (Thousand Oaks, CA: Sage Publications), 3-47. 
Dutta, M. J. (2008). Communicating Health: A Culture-centered Approach, 1st Edn. Cambridge: Polity.

Emanuel, E. J., Onwuteaka-Philipsen, B. D., Urwin, J. W., and Cohen, J. (2016). Attitudes and practices of euthanasia and physician-assisted suicide in the United States, Canada, and Europe. JAMA 316, 79-90. doi: 10.1001/jama.2016.8499

Fairclough, N. (2013). Critical discourse analysis and critical policy studies. Crit. Policy Stud. 7, 177-197. doi: 10.1080/19460171.2013.798239

Foucault, M. (1965). Madness and Civilization: A History of Insanity in the Age of Reason. New York, NY: Vintage Books.

Foucault, M. (1998). "Sex, power and the Politics of Identity," in Ethics: Subjectivity and Truth, 1st Edn, ed P. Rabinow (New York, NY: The New Press), 163-173.

Fulcher, G. (1989). Disabling Policies?: A Comparative Approach to Education, Policy and Disability. New York, NY: Falmer Pr.

Gillespie, S. R. (2001). The politics of breathing: asthmatic medicaid patients under managed care. J. Appl. Commun. Res. 29, 97-116. doi: 10.1080/00909880128105

Goodwin, N. (1996). Governmentality in the queensland department of education: policies and the management of schools. Discourse Stud. Cult. Polit. Educ. $17,65-74$.

Harvey, D. (2000). Spaces of Hope. Berkeley, CA: University of California Press.

Ho, A. (2008). The individualist model of autonomy and the challenge of disability. J. Bioeth. Inq. 5, 193-207. doi: 10.1007/s11673-007-9075-0

Johannesen, J. (2016). Why Bill C-14 Must Include The "Reasonably Foreseeable Death" Clause. Retrieved from: Jennifer Johannesen website: http://johannesen. ca/2016/06/bill-c-14-must-include-reasonably-foreseeable-death-clause/ (acccessed April 7, 2018).

Kafer, A. (2013). Feminist, Queer, Crip. Retrieved from: http://muse.jhu.edu/book/ 23617 (accessed June 18, 2018).

Keränen, L. (2007). "Cause Someday We All Die": rhetoric, agency, and the case of the "Patient" preferences worksheet. Quart. J. Speech 93, 179-210. doi: $10.1080 / 00335630701425100$

Legg, S. (2005). Foucault's population geographies: classifications, biopolitics and governmental spaces. Popul. Space Place 11, 137-156. doi: 10.1002/psp.357

Lunn, S. (2016). Assisted-dying Bill "Worse Than Nothing," Says Lawyer Who Argued Carter Case. Retrieved from: https://www.cbc.ca/news/politics/josepharvay-assisted-dying- 1.3568438 (accessed July 12, 2018).

Lupton, D. (1995). The Imperative of Health: Public Health and the Regulated Body. Sage.

Lupton, D. (2003a). Medicine as Culture: Illness, Disease and the Body in Western Societies. Retrieved from: http://www.123library.org/book_details/?id=440

Lupton, D. (2003b). "The social construction of medicine and the body," in The Handbook of Social Studies in Health and Medicine, eds G. L. Albrecht, R. Fitzpatrick, and S. C. Scrimshaw (Thousand Oaks, CA: SAGE), 50-63.

McLeod, M. (2016). Medically Assisted Dying Bill Ignores Those Trapped in Suffering: Family. In CTV News. Retrieved from: https://www.ctvnews.ca/ canada/be-afraid-of-bill-c-14-right-to-die- pioneer-kay-carter-s-familyspeaks- out- 1.2933329

Mennicken, A., and Miller, P. (2012). Accounting, territorialization and power. Foucault Stud. 4-24. doi: 10.22439/fs.v0i13.3503

Metzl, J. M., and Kirkland, A. (eds.). (2010). Against Health: How Health Became the New Morality. New York, NY: NYU Press.

Mitchell, D. T., and Snyder, S. L. (1997). The Body and Physical Difference: Discourses of Disability. Ann Arbor, MI: University of Michigan Press. doi: 10.3998/mpub.11114

Mokros, H. B., and Deetz, S. (2013). "What counts as real?: a constitutive view of communication and the disenfranchised in the context of health," in Communication and Disenfranchisement: Social Health Issues and Implications, ed E. B. Ray (New York, NY: Routledge), 29-44.

Murphy, M. (2012). Seizing the Means of Reproduction: Entanglements of Feminism, Health, and Technoscience.

Nadesan, M. H. (2013). Constructing Autism: Unravelling the "Truth" and Understanding the Social. New York, NY: Routledge.

Nicol, J., and Tiedemann, M. (2016). Legislative Summary of Bill C-14: An Act to amend the Criminal Code and to Make Related Amendments to Other Acts (Medical Assistance in Dying). Retrieved from: https://lop.parl.ca/About/ Parliament/LegislativeSummaries/bills_ls.asp?Language $=E \& l s=c 14 \&$ Parl $=$ $42 \&$ Ses $=1 \&$ source=library_prb (accessed April 7, 2018).

Osborne, T. (1997). Of Health and Statecraft. in Foucault, Health and Medicine, eds A. R. Petersen and R. Bunton (London: Psychology Press), 173-188.
Parliament of Canada (1982). Canadian Charter of Rights and Freedoms. Ottawa, ON: Parliament of Canada.

Parliament: House of Commons (1861). Offences Against the Person Act 1861. London: Parliament: House of Commons.

Perez, T. L., and Dionisopoulos, G. N. (1995). Presidential silence, C. Everett Koop, and the surgeon general's report on AIDS. Commun. Stud. 46, 18-33. doi: 10.1080/10510979509368436

Reitmanova, S., Gustafson, D. L., and Ahmed, R. (2015). "Immigrants Can Be Deadly": critical discourse analysis of racialization of immigrant health in the canadian press and public health policies. Can J Commun. 40, 471-487. doi: 10.22230/cjc.2015v40n3a2831

Rodriguez v. British Columbia (Attorney General). (1993). 3 SCR 519.

R. v. Morgentaler. (1993). 3 SCR 463.

Sauer, R. (1978). Infanticide and abortion in nineteenth-century Britain. Pop. Stud. 32, 81-93. doi: 10.1080/00324728.1978.10412793

Saxton, M. (2013). Disability Rights and Selective Abortion. in Disability Studies Reader, 4th edn, ed L. J. Davis (New York: Routledge), 87-99.

Schweik, S. (2009). The Ugly Laws: Disability in Public (The History of Disability). New York, NY: New York University.

Seale, C. (1998). Constructing Death: The Sociology of Dying and Bereavement. Cambridge University Press. doi: 10.1017/CBO9780511583421

Seale, C. (2003). Media and Health. London: Sage.

Shapiro, M. J. (1981). Language and Political Understanding: The Politics of Discursive Practices. New Haven, NY: Yale University Press.

Shapiro, M. J. (2012). Discourse, Culture, Violence. Routledge.

Tierney, T. F. (2010). The governmentality of suicide: Peuchet, Marx, Durkheim, and Foucault. J. Classic. Sociol. 10, 357-389. doi: 10.1177/1468795X10379677

Timmermans, S. (2005). Death brokering: constructing culturally appropriate deaths. Sociol. Health Illn. 27, 993-1013. doi: 10.1111/j.1467-9566.2005.00467.x

Tremain, S. L. (2005). Foreword. In Foucault and the Government of Disability. Retrieved from: https://muse.jhu.edu/book/7108 (accessed December 19, 2018).

Van Brussel, L. (2014). "A discourse-theoretical approach to death and dying," in The Social Construction of Death: Interdisciplinary Perspectives, eds L. Van Brussel and N. Carpentier, 13-33.

Waitzkin, H. (1991). The Politics of Medical Encounters: How Patients and Doctors Deal With Social Problems. New Haven, CT: Yale University Press.

Walter, T. (1994). The Revival of Death, 1st edn. New York, NY: Routledge.

Wente, M. (2015). Should Doctors Be Allowed to Kill? The Globe and Mail. Retrieved from: http://www.theglobeandmail.com/opinion/should-doctorsbe-allowed-to-kill/article26428075/ (accessed February 11, 2016).

West, E. (2018). Invitation to witness: the role of subjects in documentary representations of the end of life. Int. J. Commun. 12, 20.

Wilson-Raybould, J. (2016). Bill, C.-,14., Pub,. L., and No,. C.-,14.

WPR: What's the Problem Represented to Be? (2014). Retrieved from: https://www. adelaide.edu.au/carst/online-modules/wpr/

Zola, I. K. (2017). The Medicalization of Aging and Disability. in The Elderly: Legal and Ethical Issues in Healthcare Policy, ed M. L. Levine (New York, NY: Routledge), 299-315.

Zoller, H., and Dutta, M. J. (2009). Emerging Perspectives in Health Communication: Meaning, Culture, and Power. Cambridge: Routledge. doi: 10.4324/9780203891223

Zoller, H. M. (2005). Women caught in the multi-causal web: a gendered analysis of Healthy People 2010. Commun. Stud. 56, 175-192. doi: 10.1080/00089570500078809

Zoller, H. M., and Kline, K. N. (2008). Theoretical contributions of interpretive and critical research in health communication. Commun. Yearbook, 32, 89-135. doi: 10.1080/23808985.2008.11679076

Conflict of Interest: The author declares that the research was conducted in the absence of any commercial or financial relationships that could be construed as a potential conflict of interest.

Copyright $(2019$ Pringle. This is an open-access article distributed under the terms of the Creative Commons Attribution License (CC BY). The use, distribution or reproduction in other forums is permitted, provided the original author(s) and the copyright owner(s) are credited and that the original publication in this journal is cited, in accordance with accepted academic practice. No use, distribution or reproduction is permitted which does not comply with these terms. 